\title{
REIFICAÇÃO: UMA CATEGORIA REFORMULADA PELA TEORIA CRÍTICA?
}

\author{
Reification: a category reformulated by critical theory?
}

\section{Marcio Renan Hamel}

UPF

Resumo: A presente pesquisa analisa a reformulação da categoria da reificação pela teoria crítica. O traballho reconstrói, inicialmente, a percepcão de reificaça presente na filosofia de Georg Lukács. No segundo momento, investiga a proposta de refomulação operada por Honneth e, em terceiro instante, trabalha a concepção do comportamento reificador na teoria de Fraser. No quarto passo, analisa algumas críticas opostas à reformulação de Honneth. Por fim, conclui positivamente quanto à reformulação apresentada por Honneth, bem como defende que a utilização do conceito realizada por Fraser está próxima ao entendimento honnethiano, mas com alguma diferença conceitual.

Palavras-chave reificação; reconhecimento; marxismo; status.

Abstract: This research analyzes the refomulation of the reification category by critical theory. The work reconstructs, initially, the perception of reification present in the philosophy of Georg Lukács. In the second moment, investigates the proposal of reformulation operated by Honneth. In the third moment, it works the conception of reifier behavior in Fraser's theory. In the fourth step, it analyzes some opposing criticisms of Honneth's reformulation. Finally, it concludes positively with Honneth's reformulation, as well as arguing that Fraser's use of the concept is close to Honneth's understanding, but with some conceptual difference.

Keywords: reification; recognition; Marxism; status.

\section{Introdução}

O conceito de reificação aparece principalmente nos escritos do jovem Marx, com consideraçöes posteriores pelo Marx maduro ao trabalhar a ideia de mercadoria. 0 desenvolvimento filosófico da referida categoria talvez tenha sido melhor trabalhado por Georg Lukács, considerado o principal filósofo do marxismo ocidental. Lukács explorou o conceito em sua obra História e Consciência de Classe, onde aparece, inclusive, uma nova forma de compreensão do marxismo ao início do recém findo século XX.

Recentemente, a discussão acerca do conceito de reificação retorna à teoria crítica principalmente pela atualização oferecida por Axel Honneth à categoria. Por outro lado, Nancy Fraser também vem oferecendo uma ou outra referência sobre a reificação. De maneira particular, a partir do profícuo debate existente entre ambos, principalmente pelo conjunto de artigos publicados em ¿Redistribución o Reconocimiento? (2006), onde Honneth e Fraser procuram discutir uma compreensão de justiça suficiente, capaz de englobar as questōes que se projetam na época fordista, tais como lutas pela distribuição, bem como aquelas que são projetadas na atualidade como lutas por reconhecimento.

Enquanto Honneth trabalha o reconhecimento enquanto uma categoria moral fundamental, onde a ideia de distribuição aparece como derivada ou em segundo plano; Fraser nega que a distribuição possa subsumir-se ao reconhecimento, propondo uma teoria da justiça marcadamente dualista, a qual considera as duas perspectivas como dimensöes 
cofundamentais e mutuamente irredutíveis da justiça. Além dessa interessante discussão, parece que ambos acabam por disputar também a herança intelectual da teoria crítica que vem a partir da obra e do pensamento de Jürgen Habermas, considerando a forte ligação que possuem com este filósofo alemão, anteriormente assistente de Theodor Adorno.

Em que pese o importante debate teórico-filosófico existente entre Honneth e Fraser, não é objetivo da presente pesquisa revisitar esta discussão e seus pontos de desacordos. A partir desse quadro, a presente investigação procura, primeiramente, esclarecer a partir do modo como Lukács trabalha o conceito de reificação para, depois, analisar como Honneth compreende a categoria, a partir da sua teoria do reconhecimento social, bem como verificar a maneira pela qual Fraser incorpora a ideia do comportamento reificante em sua teoria da justiça de dupla perspectiva; reconhecimento e redistribuição. Em segundo lugar, a pesquisa visa à refletir sobre a possível positividade da atualização ou reinterpretação da categoria da reificação, oriunda dos escritos de Marx, para sustentar um teoria da justiça na atualidade. Destaca-se, entretanto, que a presente pesquisa não tem por objetivo fazer e, tampouco, oferecer uma discussão sobre o marxismo ou, simplesmente, mais do mesmo, como reiteradamente se encontra. Trata-se de vislumbrar uma atualização significativa para as sociedades contemporâneas, pós-socialistas e pós-convencionais, acerca de uma categoria importante desenvolvida inicialmente pelos escritos da juventude de Marx.

Para percorrer o referido caminho, o texto está dividido em três seções, quais sejam: a primeira seção aborda a categoria central objeto de análise a partir da obra de Lukács e sua compreensão; a segunda seção trata da categoria da reificação a partir dos escritos de Honneth: a terceira seção busca esclarecer como Fraser entende o comportamento reificador. Quanto à metodologia, no domínio filosófico, esta não ocorre em separado da própria atividade de pensamento. Por essa razão se diz que a questão do método já significa uma questão de pensamento. A pesquisa se faz pelo emprego do método analítico, referindo-se à análise conceitual e à busca pelo emprego rigoroso de conceitos. O procedimento metódico de tal análise caracteriza-se pelos seguintes momentos: análise e esclarecimento de conceitos: identificação da ideia-chave; identificação de teses e argumentos; identificação de problemas e inconsistências argumentativas; tentativa de resumo e reconstrução pessoal do texto; e também pelo método hermenêutico-fenomenológico, no qual a categoria epistemológica fundamental é a compreensão e a meta é a interpretação dos fatos.

\section{Lukács: reificação como comportamento observador}

Em História e Consciência de Classe, Lukács descreve o fenômeno da reificação muito fundamentado em O Capital de Marx. O fillósofo húngaro vê o fenômeno atrelado à mercadoria, considerando que o fetichismo da mercadoria é algo próprio do capitalismo moderno. Lukács entendeu que é somente como categoria universal de todo o ser social que a mercadoria pode ser compreendida em sua essência autêntica.

Conforme apontam Camargo e Souza (2012, p.167), nesta obra inovadora de um novo modo de compreensão do marxismo do século XX, mostraram-se centrais os conceitos de totalidade e reificação. Para Lukács estes conceitos confirmaram a visão de que o método é a questão central em Marx. Na primeira seção do capítulo A reificação e a consciência do proletariado, o filósofo húngaro já emite a seguinte argumentação acerca do conceito:

A essência da estrutura da mercadoria já foi ressaltada várias vezes. Ela se
baseia no fato de uma relação entre pessoas tomar o caráter de uma coisa e,
dessa maneira, o de uma "objetividade fantasmagórica" que, em sua
legalidade própria, rigorosa, aparentemente racional e inteiramente fechada,
oculta todo traço de sua essência fundamental: a relação entre os homens.
Não pertence ao âmbito deste estudo analisar o quanto essas problemática
tornou-se central para a própria economia e quais consequências o abandono
desse ponto de partida metódico trouxe para as concepções econômicas do
marxismo vulgar. Nosso objetivo é somente chamar a atenção - pressupondo
as análises econômicas de Marx - para aqueles problemas fundamentais que
resuiltam do caráter fetichista da mercadoria como forma de objetividade, de 
uim lado, e do comportamento do sujeito submetido a ela, de outro. Apenas quando compreendemos essa dualidade conseguimos ter uma visão clara dos problemas ideológicos do capitalismo e do seu declínio (L̄ŪKÁCS, 2003, p. 194).

Apenas em tal contexto a reificação surgida da relação mercantil adquire uma importância decisiva, tanto para o desenvolvimento objetivo da sociedade, quanto para a atitude dos homens a seu respeito, para a submissão de sua consciência às formas nas quais essa reificação se exprime (LUKÁCS, 2003, p.198). A categoria da reificação passou a significar o processo por meio do qual os produtos da atividade e do traballho humano se expressam como um modelo estrutural o qual é coisificado, independente e estranho aos homens, passando a dominá-los por leis de existência externa ao sujeito (CAMARGO; SOUZA, 2013, p.168). Como o processo de trabalho é progressivamente racionalizado e mecanizado, a falta de vontade é reforçada pelo fato de a atividade do traballhador perder cada vez mais seu caráter ativo para tornar-se uma atitude contemplativa (LUKÁCS, 2003, p.204).

Note-se, também, que Lukács argumenta qual é o papel do direito e do Estado moderno em meio ao processo de produção capitalista, momento em que ele diz que "o desenvolvimento capitalista criou um sistema de leis que atendesse suas necessidades e se adaptasse à sua estrutura, um Estado correspondente, entre outras coisas" (2003" p.214). Trata-se, na verdade, de uma sistematização racional de todas as regulações jurídicas da vida, por meio de um sistema jurídico fechado e que pode se relacionar com todos os casos possíveis e imagináveis. Lukács consegue perceber e, ao mesmo tempo, denunciar a objetividade da estrutura jurídica moderna, garantida por meio de uma dogmática puramente jurídica.

Na análise de Honneth (2018, p.35), os conceitos de contemplação e indiferença são indispensáveis para a produção da reificação em outros âmbitos da ação social. Nesse contexto o sujeito produtor não participa mais do momento ativo de seu mundo circundante, colocandose, tão-somente, como observador neutro não sendo afetado psíquica ou existencialmente pelos eventos do processo de produção.

Honneth argumenta que para Lukács a reificação é algo que se refere à relação dos indivíduos consigo próprios, com os outros e com a natureza, a partir de onde tais relações são tomadas enquanto relações com coisas, em decorrência da universalização da forma mercadoria (CAMARGO; SOUZA, 2012, p.173).

\section{Reificação como esquecimento do reconhecimento em Axel Honneth}

De acordo com Honneth (2018, p.24), após a Segunda Guerra Mundial a categoria reificação perdeu posição central para produção do diagnóstico do tempo, devido ao choque causado pelo holocausto culminando com o enfraquecimento especulativo de diagnósticos de amplo alcance para a sociedade. A partir deste quadro, teóricos sociais e filósofos se concentraram mais na análise dos déficits das democracias do pós-guerra e de justiça, sem retornos a conceitos como reificação. A teoria do reconhecimento social de Honneth busca reformular o conceito de reificação de Lukács, considerando que nas últimas três décadas as teorias da justiça e as teorias sociais se limitaram a medir se as ordenações normativas da sociedade poderiam satisfazer determinados princípios de justiça (2018, p.128-129).

Enquanto representante da teoria crítica Honneth entende existir limites na teoria marxista da sociedade, onde em sua maior parte o erro fatal apontado por ele reside desde seu começo até o passado recente, entre o que Marx e seus sucessores mantiveram uma tendência histórico-filosófica a ver somente o proletariado como a quintessência de todo o descontentamento social. No entanto, Honneth chama a atenção ao fato de que há de evitar esta tendência de definição dogmática, interpretando os movimentos sociais como indicadores empíricos desse descontentamento (2006, p.100).

Honneth alega que as interpretações oferecidas sobre a categoria da reificação estão inseridas numa má compreensão da teoria de Marx, onde é explicada enquanto um conceito da explicação materialista dos processos sociais de desenvolvimento (Althusser), ou ela é interpretada como tentativa promissora de crítica ética ao capitalismo (marxismo analítico) 
(2008, p.68). Para Honneth, as duas tradições compreendem mal o empreendimento teórico de Marx, sendo que os conceitos de alienação, reificação e fetichismo permanecem incompreensíveis enquanto eles forem compreendidos como simples conceitos da explicação sociológica ou enquanto instrumentos da crítica moral.

Contra essas tradições interpretativas, ele argumenta que "o interesse específico de Marx está voltado para a compreensão das condições de vida de nossa sociedade como caulsa para uma deformação das habilidades humanas da razão" (2008, p.69). A análise da reificação de Lukács contém também um conteúdo normativo, porém evita empregar o vocabulário moral (2018, p.29). Para Honneth, Lukács trabalha uma compreensão ontologizante do conceito de reificação, ao afirmar que reificação significa que uma relação entre pessoas assume o caráter de uma coisidade (2018, p.31). Nesse sentido, em interpretação a Lukács,

a reificação pressupõe que nós nem percebemos mais nas outras pessoas as suas características que se tornam propriamente exemplares do gênero humano: tratar alguém como uma "coisa" significa justamente tomá-la(o) como "algo", despido de quaisquer características ou habilidades humanas (HONNETH, 2008, p.70).

Obviamente, por razões morais, diz Honneth, não se pode tratar pessoas como coisas, no entanto, tal ideia não faz justiça ao peso sócio-ontológico do conceito reificação, pois "alguém que reifica pessoas não atenta apenas contra uma norma, mas comete um erro mais fundamental porque ele atenta contra as condições elementares que estão na própria base do nosso discurso sobre a moral" (2008, p.70).

A questão está colocada para Honneth não mais como um contraste entre práxis reificada e um mundo objetivamente distorcido pelo próprio modo de produção, mas sim enquanto relação de um sujeito com outro sujeito $e$, dessa maneira, como algo intersubjetivamente situado (CAMARGO; SOUZA, 2012, p.173). Argumentam os autores que haveria, assim, um viés não produtivista no próprio pensamento de Lukács, no momento em que o filósofo húngaro associa a reificação igualmente a estados psíquicos de contemplação e indiferença: "Isto é, o sujeito portador de ação, não apenas toma o outro sujeito como parte do mundo das coisas em sua interação, mas se torna passivo e desinteressado diante do mundo, dos outros, e de si mesmo".

Honneth aponta para o fato de que Lukács "compreende sob o termo reificação o hábito ou o costume de um comportamento meramente observador, em cuja perspectiva o mundo circundante natural, o mundo das relações sociais e as próprias capacidades pessoais são apreendidas apenas com indiferença e de um modo neutro em relação aos afetos, ou seja, como se possuíssem as qualidades de uma coisa" (p.37). A reificação, comenta Honneth, crỉa um comportamento que distorce a própria perspectiva, propagando-se nas sociedades capitalistas onde se pode falar em uma segunda natureza do próprio homem.

Pode-se afirmar que a tese de Honneth sobre o reconhecimento reside na defesa que ele faz de que a especificidade do comportamento humano reside na atitude comunciativa que acompanha a doação da perspectiva do outro, sendo que tal capacidade de assumir a perspectiva do outro está ancorada numa interação prévia, a qual carrega os traços de uma preocupação existencial (2018, p.61).

Por isto, segundo observa Dalbosco $(2010$, p.40), justificar a tese do primado do reconhecimento significa tomar evidente a ideia de que o comportamento humano específico consiste na postura comunicativa do assumir a perspectiva (Perspektivübernahme). Dessa forma, o espaço ocupado por Honneth na teoria de Lukács é o do reconhecimento elementar e da compreensão da práxis humana enquanto teoria social, capaz de justificar uma postura intersubjetiva do sujeito agente.

A pergunta que norteia a presente investigação acerca da atualização do conceito de reificação é colocada por Honneth da seguinte maneira: "como um conceito de reificação pode hoje ser formulado mais uma vez levando em consideração, da maneira mais ampla possível, as intuições originárias de Lukács?" (2018, p.80). 
Honneth empreende uma interpretação do conceito de Lukács onde o processo pelo qual o conhecimento em relação aos outros sujeitos não alcança mais o grau de consciência necessários ao reconhecimento prévio. Isto é, o momento do esquecimento ou amnésia do próprio ato de reconhecimento passa a ser definido como comportamento reificante: "na medida em que na efetuação de nosso conhecimento perdemos o vestígio de que este se deve à nossa adoção de uma postura de reconhecimento, desenvolvemos a tendência de perceber os outros seres humanos meramente como objetos insensíveis" (2018, p.87).

Para Lukács, o conceito de reificação significou tanto um processo quanto um resultado. Pode-se descrever o processo de uma perda, a substituição de uma atitude originária e correta por uma secundária e falsa; já o resultado desse processo é uma percepção ou comportamento reificado. (2018, p.80-81).

Honneth entende a categoria reificação enquanto esquecimento do reconhecimento, ou seja, aqui ideia tem um apelo fortemente afetivo e não cognitivo. O caráter cognitivo está presente no reconhecimento jurídico, enquanto que a ideia reificante seria o esquecimento do reconhecimento afetivo ou antecedente.

\section{A reificação na teoria de status de Nancy Fraser}

A filósofa norte-americana Nancy Fraser também enquanto representante da teoria crítica vem defendendo uma significativa teoria da justiça, a qual do mesmo modo reivindica reconhecimento, mas não abrindo mão da defesa de vuma justiça distributiva. Por um lado, ela sustenta o fato de que o capitalismo globalizado acelera os contatos transculturais, sendo que, ademais, após o fatídico 11 de setembro, as lutas por religião, nacionalidade e gênero restam inter-relacionadas, de tal sorte que é impossível ignorar as demandas por reconhecimento.

Por outro lado, Fraser (2006, p.14) sustenta que as questões por justiça distributiva não desapareceram. Contrariamente, as questões econômicas aumentam, em meio as forças neoliberais que promovem uma globalização empresarial que debilitam as estruturas dos governos que tentavam certa distribuição dentro de seus países. Nesse sentido, Fraser entende que a premissa para uma compreensão suficiente da justiça deve conter dois requisitos, quais sejam: aqueles que se projetam desde a época fordista como lutas por distribuição e aqueles que se projetam atualmente como lutas por reconhecimento.

A forma paradigmática de conflito político ao longo do século XX é a luta pelo reconhecimento. Demandas por reconhecimentos das diferenças nutrem a luta de grupos sob bandeiras da nacionalidade, etnicidade, raça, gênero e sexualidade. O contexto requer uma teoria crítica do reconhecimento, isto é, uma teoria que identifique e defenda versões de política cultural da diferença a qual possa ser combinada com a política social da desigualdade (FRASER, 1995, p.69).

Para Fraser a distribuição não pode subsumir-se ao reconhecimento, propondo uma perspectiva teórica dualista a qual considera as duas dimensões fundamentais e irredutíveis da justiça, sendo a luta pela distribuição de um lado e a luta pelo reconhecimento de outro. Em sua leitura, a justiça requer tanto redistribuição quanto reconhecimento, sendo que nenlhum deles, sozinho, é suficiente.

Em sua teoria da justiça social Fraser $(2003$, p.36) propõe uma combinação entre o reconhecimento como uma questão de justiça, sustentando para tal um modelo ao qual ela denomina de status de reconhecimento. O modelo de status apresenta, segundo Fraser, quatro vantagens potenciais, quais sejam: a) permite justificar as reivindicações de reconhecimento como moralmente vinculantes nas atuais condições modernas de pluralismo de valores; b) evita a psicologização, pois o reconhecimento errôneo é uma questão de impedimentos externamente manifestados e publicamente verificáveis que se opõe a que algumas pessoas sejam membros plenos da sociedade; c) evita o ponto de vista que sustenta que todos tem o mesmo direito a estima social, pois entende que todos possuem o mesmo direito de alcançar a estima social em justas condições de igualdade e oportunidade; d) facilita a integração das reivindicações de reconlhecimento com as reivindicações de redistribuição de recursos e da riqueza. 
O modelo do status considera, ainda, que é a igualdade participativa como uma norma que deve ser aplicada de forma dialógica, em processos democráticos de deliberação pública. Segundo argumenta Fraser, "representa a principal linguagem da razão pública, a principal linguagem para desenvolver uma argumentação política democrática sobre problemas de distribuição e de reconhecimento" (2003, p.48). A meu ver é neste ponto que Fraser mais se aproxima da filosofia social e política de Habermas, principalmente no que diz tange à democracia deliberativa.

Fraser chama a atenção para o fato de que o marxismo já não é uuma força a ter em conta, porquanto fora superado pelos paradigmas culturalistas, tanto na política quanto na universidade. Nesse sentido, alega que é menos provável que a teoria crítica sucumba ao economicismo ortodoxo ou a amnésia neoliberal que reprime a crítica da economia política (2003, p.159). Também reconhecendo a insuficiência da teoria marxiana quanto à problemas contemporâneos, Fraser igualmente absorve a categoria da reificação em sua teoria da justiça.

Atualmente, a tarefa do pensamento crítico deve estar necessariamente vinculada a um novo contexto social. Por isso, Fraser sustenta que hoje em dia quem se propõe ao projeto de uma teoria crítica enfrenta uma nova tarefa impressionante, de maneira que a diferença em relação à primeira geração da Escola de Frankfurt reside no fato de que hoje não se pode dar por suposta uma cultura política em que as esperanças emancipatórias encontram seu ponto central no socialismo. Em troca, enfrenta-se um esgotamento das energias utópicas e uma proliferação descentrada de movimentos sociais, muitos dos quais buscam reconhecimento da diferença e igualdade econômica.

Por óbvio, Fraser está fazendo a leitura do que Habermas já denominou de esgotamento das energias utópicas, quiando ele já sustentou não só o fracasso da esquerda e sua necessidade de revisão, bem como o colapso do Estado social: "E isto faz com que as energias da utopia da sociedade de trabalho se esgotem" (HABERMAS, 1997, p.129). Na Ideologia Alemã, Marx perseguiu o mesmo tipo de utopia da sociedade de trabalho: "Chegou-se a tal ponto, portanto, que os indivíduos devem apropriar-se da totalidade existente de forças produtivas, não apenas para chegar a autoatividade, mas simplesmente para assegurar a sua existência" (ENGELS; MARX, 2007, p.73)。

Entretanto, diz Habermas, hoje em dia, a utopia da sociedade de traballho não possui mais força de convicção, não somente porque as forças de produção perderam sua inocência ou porque a propriedade privada dos meios de produção não recai na autoadministração do trabalho. "Antes de tudo, a utopia perdeu o seu ponto de referência na realidade: a força de trabalho abstrato, configuradora das estruturas e formadora da sociedade" (HABERMAS, 2005, p.118).

Fraser sustenta que as lutas por reconhecimento estão proliferando na atualidade, especialmente quando os fluxos migratórios e dos meios globais estão fraturando e tornando híbridas todas as formas culturais, incluindo as consideradas antes intactas. No entanto, algumas lutas por reconhecimento procuram adaptar adequadamente as instituições a esta condição de maior complexidade e outras muitas adotam uma forma de um comunitarismo que simplifica e coisifica de maneira drástica as identidades de grupo. Nesse quadro, as lutas por reconhecimento não promovem uma interação respeitosa por meio das diferenças em contextos cada vez mais multiculturais (2003, p.87).

Dessa maneira, tais lutas "tendem a fomentar o separatismo e a preservação de grupos, o chauvinismo e a intolerância, o patriarcalismo e o autoritarismo. Chamo a este o problema da reificação" (2003, p.87). Para Fraser, na medida em que a política de reconhecimento está coisificando as identidades coletivas, corre o risco de sancionar violações de direitos humanos e congelar antagonismos aos quais pretendia mediar.

Segundo Fraser, o modelo da política de reconhecimento que ela denomina de modelo da identidade, se ampara no pensamento de Hegel, principalmente no fato de que a identidade é construída na forma de diálogo, por meio de um processo de reconhecimento mútuo. Segundo Hegel, o reconhecimento marca aí uma relação recíproca ideal entre os sujeitos, onde cada um vê o outro como seu igual. Nesse caso, não ser reconhecido é sofrer uma distorção da relação de alguém consigo próprio, ao mesmo tempo em que é um dano à identidade do sujeito. O referido modelo também tende a reificar a identidade, pois ao frisar a obrigatoriedade da 
elaboração de identidade coletiva autêntica, auto afirmativa e autogerada, o modelo da identidade acaba por incutir pressão moral nos membros individuais a fim de adaptarem-se a uma cultura de determinado grupo social (2000, p.110-112).

Logo, o modelo da identidade serve como um meio para o não-reconhecimento, uma vez que ao reificar a identidade grupal, torna sombreada a política de identificação cultural. Fraser entende o modelo identitário do reconhecimento como profundamente defeituoso, pois é teoricamente deficiente e politicamente problemático, vez que equipara a política de reconhecimento com a política identitária, momento em que acaba por proporcionar a reificação de identidades de grupo $(2000$, p.113). No modelo de status, o não-reconhecimento constitui uma forma de subordinação institucionalizada e, dessa maneira, uma violação séria da justiça.

De maneira distinta do modelo da identidade, o modelo de status trabalha a justiça social enquanto abrangência das duas dimensões já elencadas: uma dimensão de reconhecimento, a qual diz respeito aos efeitos de significados institucionalizados e normas sobre a posição relativa dos atores sociais; e uma dimensão de distribuiç̧ão, a qual envolve a alocação de recursos disponíveis aos atores sociais (2000, p.116).

Dessa forma, o modelo do status evita reificar identidades grupais, porquanto o que exige reconhecimento nesta consideração não é a identidade específica de grupo, mas o status dos indivíduos como parceiros integrais da interação social (2000, p.119). Portanto, "o falso reconhecimento consiste na depreciação de tal identidade pelo grupo dominante e no consequente dano infligido ao sentido do eu dos membros do grupo" (FRASER, 2002, p.14). Para o modelo de status o falso reconhecimento é uma relação social de subordinação transmitida por meio de padrões institucionalizados de padrões culturais.

No modelo de status do reconhecimento, a ideia de reificar a cultura significa, assim, ignorar as interações cullturais, tratando as culturas como profundamente definidas, separadas e não-interativas. Por isso, o modelo da identidade tem como resultado a promoção do separatismo e o enclausuramento de grupos, ao invés de fomentar a interação entre eles $(2007$, p.107). Por isso:

- modelo de status evita reificar a culltura - sem negar a sua importância política. Atento ao fato de que os padrões institucionalizados de valoração cultural podem ser veículos de subordinação, ele procura desinstitucionalizar os padrões que impedem a paridade de participação e os substituiem por padrões que a promovam (2007, p.109).

Nancy Fraser embora se utilize da categoria da reificação acaba por não desenvolver uma compreensão particular sobre o conceito. Neste ponto, pode-se dizer que Fraser trabalha a categoria muito próxima do entendimento de Honneth, não havendo grandes contribuições nesse sentido, considerando que, ao contrário de Honneth, Fraser não diz o que entende por reificação, enquanto Honnneth desenvolveu artigos e obra específica sobre o tema. No entanto, pode-se fazer tal conclusão a partir de uma dedução fraca, considerando-se que Fraser, assim como Honneth, também desenvolve uma teoria do reconhecimento social e que ao empregar o conceito reificação está se referindo a negação de identidades.

\section{Um novo olhar sobre uma velha ideia?}

Parece adequado nomear esta última seção com o próprio título da obra de Honneth, onde ele afirma ser a reificação um novo olhar sobre uma velha ideia, a fim de possibilitar a análise da atualização da categoria na teoria do reconhecimento social. O propósito da presente investigação visa a responder se a nova leitura pode ser considerada uma atualização do conceito tanto na obra de Honneth quanto nos textos de Fraser e, nesse sentido, vislumbrar até que ponto a teoria crítica consegue trabalhar o conceito de reificação no interior das relações sociais das sociedades contemporâneas.

Segundo observa $\mathbb{D} a l b o s c o$ (2010, p.39), no que diz respeito a reinterpretação oferecida por Honneth, a questão a ser colocada é a de saber se com o desacoplamento do conceito de 
práxis humana de sua base econômica junto a inserção do referido conceito no âmbito de uma teoria do primado do reconhecimento, ele ainda consegue alcançar as dimensões concretamente desfiguradas que a práxis humana assume em contextos sócio-culturais mercantilizados do mundo contemporâneo.

Nesse sentido, Honneth entende que Lukács se tornou um filósofo importante para o pensamento crítico contemporâneo a partir do momento em que empregou de maneira original, o conceito de reificação para investigar a sociabilidade de sua época e o modo pelo qual se dava a condição humana. Lukács se deixou influenciar de forma excessiva pelo modelo de troca de mercadorias, ao que atribuiu um caráter totalizador ao fenômeno da reificação, do qual só foi possível se livrar recorrendo ao idealismo do sujeito ativo (DALBOSCO, 2010, p.40).

Na leitura de Dalbosco, a estratégia oficial de Lukács o conduziu para uma compreensão da práxis humana principalmente a partir da relação sujeito-objeto, no qual o próprio sujeito assume a posição de mero observador, fato que lhe bloqueou o caminho para duas descobertas significativas, quais sejam: "do reconhecimento elementar e da compreensão da práxis humana nos termos de uma teoria social capaz de justificar a postura intersubjetiva do sujeito agente" (2011, p.40). São essas duas descobertas que, conforme Dalbosco, Honneth toma como referência para atualizar o conceito de reificação, tratando-o enquanto forma de esquecimento do reconhecimento.

Ao invés de pensar a reificação, tão-somente, enquanto a descrição da produção alienada do objeto por parte de um sujeito que foi excluído da coletividade, Honneth progride a partir daquelas passagens do texto de Lukács em que a práxis verdadeira pode ser entendida como atitude intersubjetiva (MELO, 2010, p.239). Será exatamente esta atitude subjetiva, a qual se caracteriza por participação ativa e envolvimento existencial em contraponto à contemplação e indiferença, que Honneth fundamenta com base na categoria do reconhecimento. A função da categoria do reconhecimento preencheria um vazio deixado por Lukács.

Além de manter o endosso da necessidade da teoria crítica, Honneth também defende o vínculo dessa com a psicanálise. Segundo interpretação de Saavedra (2008, p.25), na obra Reificação Honneth introduz uma nova dimensão em sua teoria, qual seja, a dimensão existencial do reconhecimento. Em Luta por Reconhecimento, ele apresenta pela primeira vez sua teoria de forma sistemática, desenvolvendo um conceito negativo de reconhecimento. "Negativo significa aqui que Honneth não pretende em primeira mão, definir o que significa reconhecimento, mas que ele pretende, a partir de uma análise das experiências de desrespeito, comprovar de forma dialética a necessidade das relações de reconhecimento" (2008, p.27).

Foi somente no debate com Nancy Fraser que Honneth definiu de forma clara os contornos das dimensões social e antropológicas de sua teoria, de maneira que passa a defender a tese de que a dimensão antropológica não pode ser definida a priori. Ao contrário, será somente no último estágio das esferas de desenvolvimento que se definirá a dimensão antropológica do reconhecimento, cujo objeto é a análise da natureza intersubjetiva dos seres humanos (SAAVEDDRA, 2008, p.24-28).

Na análise de Judith Butler (2018, p.134), Honneth percebe que a reificação não contempla somente o fato de um sujeito tratar os seres humanos como objetos, onde os objetos são entendidos a partir do modelo de mercadoria, mas de os próprios sujeitos considerarem a si mesmos de maneira reificadora. Honneth tem como objetivo delinear a estrutura de uma "práxis genuína", isto é, um engajamento com os outros e com o mundo circundante, que implica também alterações nas disposições e atitudes dos sujeitos. "Participar significa, portanto, adotar a posição do outro" (BUTLER, 2018, p.140).

Conforme Butler,

a dimensão da psicologia e da psicanálise à qual Honneth procuira recorrer é a da teoria da vinculação. Mas ele lê essa teoria apenas de maneira seletiva. Na medida em que a vinculação é uma precondição ao desenvolvimento uma tese com a qual concordo plenamente -, então a differenciação é uma tarefa que nos engaja por toda a vida e que configura a estrutura permanente 
de um certo dilema ético: como permanecer vinculado e também ser um self delimitado ou separado? (BUTLER, 2018, p.145).

Por seu turno, Honneth esclarece o que significa "esquecer" quanto ao modo antecedente do reconhecimento, redefinindo reificação como forma de esquecimento:

Estou convencido de que é mais fácil responder a essa pergunta ao se esclarecer que o termo "esquecer" não possui um significado tão forte quanto aquele usado muitas vezes na expressão "desaprender"; não se trata aqui de simplesmente retirar da consciência aquele fato do reconhecimento e dizer que este "desapareceu", mas se trata antes de certa diminuição da atenção que leva tal fato ao pano de fundo da consciência a ponto de o perdermos de vista. Portanto, reificação no sentido de um "esquecimento do reconhecimento" significa deixar de dar atenção ao fato de quie, na efetuação do conhecimento, o próprio ato de conhecer é tributário de um reconhecimento prévio. $(2018, \mathrm{p} .89)$.

Para Butler (2018, p.161) a força de tal estipulação reside no fato de que a consciência é, por definição, ligada ao reconhecimento. Por isso, as formas de reificação que podem ter superado as relações de reconhecimento só podem ser um tipo ou forma de aparência. Butler entende que tais estipulações não podem ser provadas. Por outro lado, ela entende que Honneth tenta argumentar que os seres humanos não podem adotar uma postura reificadora frente aos outros sem perder de vista seu reconhecimento precedente das outras pessoas, pressupondo uma relação temporal entre reconhecimento e reificação que precisa ser mellhor explicada.

Honneth preenche um vazio deixado pela teoria de Lukács, descrevendo o fenômeno da auto-reificação como um dos casos de esquecimento do reconhecimento. Esse fenômeno ocorre quando a auto-afirmação cai em esquecimento. No entanto, Honneth não deixa claro como compreender de que forma que tal dimensão existencial do reconhecimento se relaciona com a dimensão sócio-lhistórica do reconhecimento. Ademais, não fica claro também como a capacidade para a auto-afirmação e para a auto-reificação estão relacionadas ou dependem do reconhecimento do indivíduo pelo outro (SAAVEDRA, 2008, p.31).

Ainda há que se notar, ainda, que na crítica feita por Jütten (2010, p.20), Honneth insiste no fato de que a reificação é tomada como fato antropológico e a-histórico, concentrando-se muito mais no lado subjetivo do que objetivo, enfatizando, dessa maneira, o aspecto teórico da reificação em detrimento de seu aspecto cognitivo. A partir daí, a teoria do reconhecimento social deveria explicar como é possível o tratamento das pessoas como se elas fossem coisas, sem que que isso possa ser reconhecido como um dano moral.

Em outro aspecto, Jütten (2010, p.24) argumenta que para Lukács a reificação só ocorre quando a mercadoria, a produção e o intercâmbio penetram em todos os aspectos das sociedades. Essas são as circunstâncias sociais que levam as pessoas a se relacionarem consigo mesmas, com os outros e com as instituições de maneira reificada e reificadora. No momento em que Lukács escreveu História e Consciência de Classe, ele não ofereceu argumentos sobre problemas sociais específicos, pois em seu entendimento a reificação é ruim porque impede o proletariado de ver sua missão histórica mundial de derrubar o capitalismo. Lukács não vê a reificação como uma patologia social e isso é um dos maiores problemas para a filosofia social na atualidade.

Por seu turno, Jütten (2010, p.25) entende que ao início do século XXI não se pode prescindir de um fundamento normativo para a afirmação de que a reificação é uma patologia social e, o relato de Honneth, da reificação literal, fornece tal fundamento. Surge a necessidade de uma base normativa para a reificação consciente das condições sociais e históricas de sua ocorrência.

De forma geral, ainda evidencia-se uma crítica de fundo teórico mais substancial em oposição tanto à teoria do reconhecimento social de Honneth quanto à teoria do status de Fraser, no que diz respeito à compreensão marxiana que coloca as lutas por reconhecimento 
dentro do conceito de luta de classes e, a partir daí, as implicações teóricas de coerência ou alinhamento aos textos de Marx, principalmente à Ideologia Alemã, são várias.

Conforme assinala Silva (2010, p.148), tanto em Honneth quanto em Fraser, o diagnóstico da sociedade capitalista contemporânea não confere ao conceito de exploração e dominação de classe um tratamento teórico adequado. De acordo com Marx e Engels, os indivíduos só se formam como classe quanto precisam realizar uma luta em oposição à outra classe. Do contrário, as relações se limitam à ideia de concorrência. Daí o entendimento de Engels e Marx acerca das lutas por interesses:

Sendo o Estado, portanto, a forma pela qual os indivíduos de uma classe dominante fazem valer seus interesses comuns e na qual se resume toda a sociedade civill de uma época, concluil-se que todas as instituições comuns passam pela mediação do Estado e recebem uma forma política. Daí a ilusão de que a lei repousa na vontade, e, mais ainda, em uma vontade livre, destacada da sua base concreta. Da mesma maneira, o direito por sua vez reduz-se à lei. $(2007$, p. 74$)$.

Por isso, pode-se afirmar que na teoria marxiana a luta de classes será sempre uma luta pela tomada de poder político, de poder do próprio Estado, o que consiste também em ser uma luta por justiça. Ao expressar uma concepção de bem comum e, ao mesmo tempo, de bem-estar coletivo, a luta de classes se traduz numa luta de justiça. Entretanto, não será qualquer luta por justiça que poderá ser considerada luta de classes, mas tão-somente, aquela que no interior do modo de produção capitalista questiona o direito burguês (SILVA, 2010, p.150-151).

Nesse sentido, Engels e Marx (2005, p.52) demonstram que o desenvolvimento do antagonismo de classes acompanha o desenvolvimento da indústria, motivo pelo qual a situação econômica não oferece condições materiais para a emancipação do proletariado. Fíca demonstrado que o poder político é organizado por uma classe para a opressão de outra.

Para Silva, tanto Honneth quanto Fraser priorizam em suas teorias a discussão sobre o conceito de justiça, mas se afastam sobremaneira do debate político-econômico, ainda com ressalva à teoria do status de Fraser que, ao reforçar a ideia de redistribuição, acaba por ao menos permitir que lhe abra uma janela para uma reelaboração crítica do conceito de cidadania, uma vez que possibilita relacionar injustiças econômicas com desrespeitos identitários (2010, p.151).

\section{Conclusão}

A partir da presente pesquisa, pode-se afirmar, inicialmente, que tanto a teoria do reconhecimento de Honneth quanto a teoria do status de Fraser são teorias da justiça social, as quais buscam a concretização da emancipação humana, objetivo sempre presente entre os representantes da teoria crítica.

Como segunda nota conclusiva, aponta-se para o fato de que Lukács vislumbrou o fenômeno da reificação conectado à mercadoria, fazendo com que apenas no contexto mercantil a categoria adquire uma importância decisiva para o desenvolvimento social. Dessa forma, a reificação é o processo por meio do qual os produtos da atividade e do trabalho humano se expressam enquanto modelo estrutural coisificado, independente e estranho aos homens. Aqui como consequência do trabalho racionalizado a atividade laboral perde progressivamente seu caráter ativo, em prol de uma atitude meramente contemplativa.

A partir dessa relação, Lukács consegue perceber, ainda, que o direito positivo e o Estado possuem uma função de manutenção da estrutura jurídica, a qual foi garantida por meio de uma dogmática puramente jurídica, onde a sistematização racional de todas as regulações jurídicas da vida, por um sistema jurídico fechado, sustenta tal ação reificadora.

Em terceira nota conclusiva, pode-se explicar que a teoria do reconhecimento social de Honneth busca reformular o conceito de reificação agora voltando-se às relações humanas que reclamam reconhecimento. Para empreender tal reformulação, Honneth parte do pressuposto de que a teoria marxista da sociedade incorreu no erro de manter uma tendência histórico- 
filosófica de ver somente no proletariado o descontentamento social. Honneth entende que Lukács trabalhou a reificação, tão-somente, enquanto um comportamento meramente observador. No entanto, o comportamento reificante distorce a própria perspectiva do outro que reside na própria atitude comunicativa. Daí que Honneth ocupa o espaço em branco na teoria de Lukács do reconhecimento elementar, justificador de uma postura intersubjetiva do sujeito agente. Dessa forma, a reificação será o esquecimento do reconhecimento afetivo ou antecedente.

A quarta nota conclusiva reside na averiguação da utilização da categoria da reificação pela teoria do status de Fraser. Aqui a ideia de reconhecimento é trabalhada como uma questão de justiça, partindo-se de um modelo de status de reconhecimento. Da mesma forma que Honneth, Fraser vê limites no marxismo, especificamente quanto ao fato de ter sido superado por paradigmas culturalistas. A teoria do status social exige o reconhecimento justamente do status dos indivíduos enquanto parceiros da interação social, ao contrário do modelo da identidade que por sua política de reconhecimento trabalha a identidade de grupos, abrindo espaço para separatismos, intolerâncias, patriarcalismos e autoritarismos.

Nesse quadro, a teoria do status entende que ao agir assim, o modelo da identidade acaba por reificar a cultura, ignorando as interações culturais e tratando as culturas como definidas, separadas e não-interativas. Entretanto, Fraser não desenvolve uma compreensão pormenorizada acerca da categoria da reificação, ao contrário do trabalho desenvolvido por Honneth, ficando, assim, em uma apropriação superficial do conceito.

Para uma quinta nota conclusiva, necessário esclarecer algumas críticas voltadas a reformulação do conceito de reificação operado por Honneth. A proposta de reformulação da categoria é bem-vinda, mormente porque Honneth consegue a inserir em uma compreensão de práxis humana nos termos de uma teoria social, a qual consegue justificar a postura intersubjetiva do agente, deslocando-a, assim, de uma práxis humana a partir de uma relação sujeito-objeto, em que o sujeito está na posição de mero observador. Desse núcleo, pode-se deduzir que, de fato, o marxismo não conseguiu alcançar os problemas sociais relacionados à cultura, à etnia e ao reconhecimento da identidade social dos sujeitos, ficando preso à relação referente ao proletariado.

A própria categoria do reconhecimento preenche um vazio deixado por Lukács, possibilitando a Honneth manter a necessidade da teoria crítica. O espaço deixado em branco pelo filósofo húngaro passa a significar o esquecimento do reconhecimento. Ainda uma crítica levantada por Jüitten que questiona Honneth acerca do que de fato seja a reificação e se tal comportamento não se resolve na esfera de um dano moral. Ainda que seja possível a resolução da ação reificadora na esfera jurídica do dano moral, tal fato não deixará de ser uma reificação frente a reformulação proposta por Honneth. Entretanto, tal resolução é difícil de ser pensadla no plano jurídico-positivo, considerando-se o comportamento reificador como esquecimento do reconhecimento afetivo (antecedente). Seria o esquecimento do reconhecimento afetivo ato capaz de gerar uma reparação civil por ofensa moral?

Ao fim, uma sexta nota conclusiva, a qual evidencia a crítica feita tanto a Honneth quanto a Fraser no que diz respeito ao tratamento dado em suas teorias para o conceito de exploração e luta de classes. Reside aqui uma crítica quanto ao fato de ambos não trabalharem a ideia de luta enquanto luta pelo poder político. Nesse sentido, a presente investigação aponta para o fato de que o marxismo contemporâneo não conseguiu fazer um diagnóstico preciso da ideia geral de lutas por reconhecimento, mantendo sua análise de maneira específica em relação à superestrutura do Estado e o proletariado, o que causa um déficit sociológico ao marxismo. Por outro lado, a teoria de Fraser responde melhor ao debate político econômico, pois reforça a ideia de redistribuição, enquanto que Honneth vê esta resolução como embutida no êxito do reconhecimento.

\section{Referências}

BUTLER, Judith. Adotando o ponto de vista do outro: implicações ambivalentes. In: HONNETH, Axel. Reificação: um estudo de teoria do reconhecimento. Tradução de Rúrion Melo. São Paulo: Editora Unesp, 2018. p.133-162. 
CAMARGO, Sílvio; SOUZA, Luiz Gustavo da Cunha. Axel Honneth leitor de Lukács: reificação e reconhecimento. Pensamento Plural, Pelotas, n.11, jul/dez 2012, p.165-186.

DALBOSCO, Cláudio Almir. Reificação, reconhecimento e educação. Revista Brasileira de Educação, Rio de Janeiro, v.16, n.46, jan/abr 2010.

ENGELS, Friedrich; MARX, Karl. A ideologia alemã. Tradução de Rubens Enderle et all. São Paulo: Boitempo, 2007.

ENGELS, Friedrich: MARX, Karl. Manifest der Kommunistischen Partei. Stuttgart: Reclam, 2005.

FRASER, Nancy. A justiça social na globalização: redistribuição, reconhecimento e participação. Revista Crítica de Ciências Sociais, Coimbra, n.63, 2002, p.07-20.

FRASER, Nancy; HONNETH, Axel. ¿Redistribución o reconocimiento? Un debate políticofilosófico. Traducción de Pablo Manzano. Madrid: Ediciones Morata, 2006.

FRASER, Nancy. From Redistribution to Recognition? Dilemmas of Justice in a 'Post-Socialist' Age. New Left Review, London/UK, n.212, 1995, p.68-93.

FRASER, Nancy. Reconhecimento sem ética? Lua Nova, São Paulo, 1n.70, 2007. p.101-138.

FRASER, Nancy. Rething Recognition: overcoming displacement and reification in cultural politics. New Left Review, London/UK, n.3, mai/jun 2000, p.107-120.

HABERMAS, Jürgen. La crisis del Estado de bienestar y el agotamiento de las energias utópicas. In: Ensayos políticos. Traducción de Ramón García Cotarelo. Barcelona: Ediciones Península, 1997. p.113-134.

HONNETH, Axel. Luta por reconhecimento: a gramática moral dos conflitos sociais. Tradução de Luiz Repa. São Paulo: Ed.34, 2003.

HONNETH, Axel. Observações sobre a reificação. Civitas, Porto Alegre, v.8, n.1, jan/abr. 2008, p.68-79.

HONNETH, Axel. Reificação: um estudo de teoria do reconlhecimento. Tradução de Rúrion Melo. São Paulo: Editora Unesp, 2018.

JÜTTEN, Timo. What is Reification? A Critique of Axel Honneth. Inquiry, University of Essex, UK, 2010, v.3, n.53, p.235-256.

LUKÁCS, Georg. História e consciência de classe estudos sobre a dialética marxista. Tradução de Rodnei Nascimento. São Paulo: Martins Fontes, 2003.

MELO, Rúrion. Reificação e reconhecimento: um estudo a partir da teoria crítica da sociedade de Axel Honneth. Revista Ethica, Florianópolis, v.9, n.2, 2010, p.231-245.

SAAVEDRA, Giovani. Reificação versus reconhecimento: sobre a dimensão antropológica da teoria de Axel Honneth. Teoria e Cultura, Juiz de Fora/MG, v.2, n.1 e 2, jan./dez. 2008. p. 25-38.

SILVA, Jair Batista da. Marxismo e reconhecimento. Crítica Marxista, Campinas/SP, n.31, 2010, p.139-153.

Doutor em Ciências Jurídicas e Sociais (UFF, 2013)

Pós-Doutor em Direito (URI/RS, 2015)

Professor do PPG em Direito (UPF)

E-mail: marcio@upf.br 